\title{
Disparities in outpatient and inpatient utilization by rural-urban areas among older Mongolians based on a modified WHO-SAGE instrument
}

Vasoontara Sbirakos Yiengprugsawan ${ }^{1 *}$, Gantuya Dorj $^{2}$, Jocelyn G Dracakis ${ }^{3}$, Bilegt Batkhorol ${ }^{2}$, Undram Lkhagvaa $^{2}$, Dulamsuren Battsengel ${ }^{2}$, Chimedsuren Ochir ${ }^{2}$, Nirmala Naidoo ${ }^{4}$, Paul Kowal ${ }^{4,5}$ and Robert G Cumming ${ }^{1,3}$

\begin{abstract}
Background: Mongolia has made significant progress towards achieving Universal Health Coverage (UHC), but there are still challenges ahead with population ageing and non-communicable diseases (NCDs). The purpose of this study was to investigate patterns and determinants of outpatient and inpatient health service use amongst older people in Mongolia.

Methods: Data were collected using a questionnaire developed for the World Health Organization's Study on global AGEing and adult health (WHO SAGE). There were 478 participants from rural areas and 497 participants from Ulaanbaatar (further divided into 255 ger/yurt district and 242 apartment district residents). Multivariable logistic regression analyses were used to investigate determinants of outpatient and inpatient health service use with reported adjusted Odds Ratios (AORs) and $95 \%$ Confidence Intervals (Cls).

Results: Participants were aged 60 to 93 years. About $55 \%$ of respondents used outpatient services in the past 12 months and $51 \%$ used inpatient services in the past three years. Hypertension was the most common reason for health service use. Rural residents had longer travel times and were more likely to incur out-of-pocket expenditure (OOP). Multivariable logistic regression revealed that women were more likely to use outpatient services (AOR 1.88; 1.34-2.63). Compared to apartment residents in urban areas, ger residents in urban areas were less likely to use outpatient services (AOR 0.54; 0.36-0.83). There was no statistically significant differences in inpatient service by location. Increasing numbers of chronic conditions (1 and 2+ compared to none) were associated with both outpatient (AORs 2.59 and 2.78) and inpatient (AORs 1.97 and 3.01) service use.

Conclusions: This study highlights the needs to address disparities in outpatient service use for rural and urban ger populations. Compared with other WHO-SAGE countries, older Mongolians have relatively higher use of inpatient health care services. With a high prevalence of hypertension and an ageing population, efforts to achieve UHC would benefit from reorienting care services towards prevention and primary care management of NCDs to reduce the costs from hospital-based care.
\end{abstract}

Keywords: Aging, Equity, Low and middle-income country, Primary health care, Universal health coverage

\footnotetext{
*Correspondence: v.yiengpr@unsw.edu.au; u4199004@alumni.anu.edu.au ${ }^{1}$ Australian Research Council Centre of Excellence in Population Ageing Research (CEPAR), University of New South Wales, Sydney, Australia Full list of author information is available at the end of the article
} 


\section{Background}

Demographic and epidemiological transitions have resulted in population ageing that poses both opportunities and challenges for low and middle-income countries [1,2]. Like other countries in the Asia-Pacific region, Mongolia's population is ageing rapidly [3, 4]. The percentage of the population aged 60 years and over was $7.3 \%$ in 2018 and is predicted to increase to $12.5 \%$ in 2035 and $17.7 \%$ in 2050 [4]. Mean life expectancy at birth has increased substantially over recent years yet the country still experiences the largest discrepancy between males (66 years) and females (74 years) in the East Asia and Pacific region $[4,5]$. Chronic noncommunicable diseases pose the most predominant health challenges in Mongolia, with very high rates of primary liver cancers and cirrhosis, alongside ischemic heart disease and haemorrhagic stroke due to the high prevalence of hypertension [6-8].

Geo-politically, Mongolia is a lower middle-income country of 3.2 million people and is the second largest landlocked country in the world after Kazakhstan as well as one of the most sparsely populated [9]. Situated between China and Russia, it has been influenced by both powers but has maintained its own strong culture. Approximately half of the total Mongolian population lives in the country's only large city, Ulaanbaatar, due to internal migration. This rapid urbanising process has occurred over recent decades and as a result, economic and health inequalities exist within urban areas especially between those living in ger/yurts and apartment areas [10-12].

Mongolia has made significant progress towards Universal Health Coverage for over $90 \%$ of its population, funded by a mixed general taxation and social insurance scheme [12-14]. A 2016 assessment by the World Health Organization ranked Mongolia's UHC Index at 63 (out of 100); however, out-of-pocket expenditure contributes $32 \%$ of total health expenditure [15]. Delivery of health services is challenged by very large sparsely populated areas despite increasing urbanisation. Primary health care is delivered by Family Health Centres (FHC) in city districts and by Soum Health Centres (SHC) in rural areas. Most tertiary and all specialised hospitals are located in the capital city of Ulaanbaatar and, if referred from primary care providers, public secondary and tertiary services can be accessed free of charge. However, many patients prefer to present directly to secondary and tertiary services without appropriate referrals resulting in out-of-pocket expenditure and inequity in health service utilization [11-13]. Co-payments have also been cited as an informal feature imposed by many providers across both primary and higher levels of care in rural areas [11-13]. In addition to health system related factors, education and income inequalities have been reported to contribute to disparities in health status and health service utilization $[15,16]$.

The purpose of this study was to investigate patterns and determinants of outpatient and inpatient health service use amongst older people in Mongolia. Our analyses took into account urban-rural differences and findings could inform public health practitioners and policy makers on Universal Health Coverage and equity of service use for older Mongolians.

\section{Methods \\ Data collection}

Data were collected using questionnaires developed for the World Health Organization Study on global AGEing and adult health (WHO SAGE) $[17,18]$. In the context of this study, a few response categories (ethnicity, religion, and place of residence) were modified to correspond to Mongolia. No other changes to wording of questions were made. The survey team participated in a one-week training workshop led by an experienced WHO SAGE researcher. The survey was implemented between November 2017 and April 2018. Data were collected through face-to-face interviews using structured questionnaires and clinical assessments and took between $45 \mathrm{~min}$ and $90 \mathrm{~min}$ to complete.

\section{Selection of study subjects}

The survey sample included respondents selected from Ulaanbaatar, the only large city in Mongolia, and two rural provinces (aimag), Dundgovi and Uvurkhangai, purposively selected from the 21 aimag in Mongolia because of their proximity to Ulaanbaatar. The sampling procedures differed between Ulaanbaatar and the rural aimag. Ulaanbaatar is comprised of nine districts (düüreg) subdivided into khoroo. Four (Bayanzurkh, Chingeltei, Khan-Uul and Sukhbaatar) of the six central districts and one (Nailakh) of the three peripheral districts were randomly selected. Two khoroo were randomly selected from each of the five study districts, one ger/yurts area and one apartment area. New rural migrants to Ulaanbaatar often live-in settlements of traditional ger which are distinct from areas of more established dwellings and other infrastructure. Fifty people aged 60 years and over were randomly selected from each of the 10 study khoroo. Mongolia's rural aimag are divided administratively into soum. Four study soum were purposively selected by population size, the two with the largest (Saintsagaan and Arvaikheer) and second largest (Erdenelei and Khrakhorin) population from each of the two study aimag. In each of the four study soum, 125 people aged 60 years and older were randomly selected for the study.

In total, the final sample size was 975 people aged 60 years and older, with approximately half from urban and 
half from rural areas. The participation rate was $98.3 \%$ (99.4\% in Ulaanbaatar and $96.8 \%$ in the rural areas). With close to 500 participants in each group, the study has $80 \%$ power (p value 0.05 ) to detect a $10 \%$ prevalence difference in health service use which is of public health policy importance and also evident in other WHO SAGE countries [19] as well as between rural and urban areas in Mongolia [11, 14].

\section{Variables of interest}

The SAGE Mongolia individual questionnaire included modules on sociodemographic characteristics, health status, health service utilization and health related expenditures.

- Demographic and socioeconomic variables included sex, age, marital status, ethnicity, region, educational attainment, economic tertile (derived from annual income), and residence in rural, urban ger and urban apartment areas.

- For outpatient service use, questions included: "Over the last 12 months, did you receive any health care NOT including overnight stay in hospital or longterm care facility?" "Where did you go most often when you felt sick or needed to consult someone about your health" [public clinic including FHC and SHC, public hospital, private clinic, private hospital]?

- For inpatient health service use, questions included: "In the last 3 years, have you ever stayed overnight in a hospital or other healthcare e.g. long-term care facility?" with corresponding categories [public hospital, private hospital, and other]. The most common reasons for either outpatient or inpatient service use were broadly categorised into communicable/maternal/acute conditions, chronic joint / arthritis, heart problems, hypertension, liver cirrhosis, liver cancer and other cancers, diabetes, other internal medicine conditions, and others. The number of chronic conditions (none, 1, 2+) including diabetes, hypertension, asthma, lung diseases, heart conditions, arthritis were included as proxy for health care needs.

- Questions relating to outpatient and inpatient health service travel and payment included: mode of travel (private vehicle, taxi, walk, public transport), duration of commute and sources of payment (self, spouse, son/daughter, other family, insurance, free of charge). All respondents were asked about their satisfaction levels with how health services are conducted overall and ratings of how well services involve patients in decision making. Responses were grouped into satisfied/very satisfied, neither, dissatisfied/very dissatisfied.

\section{Statistical analysis}

Data were entered into SPSS version 17 [20] and analyses conducted using Stata version 19 [21]. Statistical differences were assessed by chi-square $\left(x^{2}\right)$ to show a relationship between categorical variables by sex and urban-rural areas and p-value of 0.05 was used to assess its statistical significance level. Selected variables for analyses were based on previous literature on factors relating to health care utilization in WHO SAGE data $[19,22]$. In addition, correlation tests were conducted for explanatory variables and the largest being 0.37 between education and rural-urban areas, there is no evidence of multicollinearity in the variables included in the model. Multivariable logistic regression analyses were used to investigate determinants of outpatient and inpatient health services use, reporting adjusted Odds Ratios (AORs) and $95 \%$ Confidence Intervals (CIs).

\section{Results}

Participants ranged in age from 60 to 93 years. There were 478 participants from rural areas and 497 participants from Ulaanbaatar (comprised of 255 ger and 242 apartment residents). Compared with the rural population, the urban population had a greater predominance of females and widows, higher levels of educational attainment, and far greater representation in the uppermost economic tertile [Table 1]. Within urban areas in Ulaanbaatar, a higher proportion of apartment residents were aged 80 years and older and were of higher socioeconomic status (education and economic tertile) as compared with ger residents. Notably, greater ethnic and religious diversity of the urban ger population reflects the presence of groups who migrated from far western Mongolia.

Approximately half of all respondents used outpatient health care in the past year [Table 2]. Use of outpatient services was lower among people living in urban ger areas (47.8\%) and rural areas (53.4\%) than among people in urban apartment areas (66.5\%). There was no statistically significant difference in outpatient service use between rural and urban ger areas but these were both statistically significantly lower than urban apartment areas. The use of public clinic facilities (FHC and SHC) was most commonly reported, followed by public hospital outpatient clinics across all groups. For inpatient healthcare utilization, approximately reported needing overnight care in the past three years [Table 2]. Overall, there was no statistically significant difference in the public versus private choices of inpatient health service use between urban and rural areas.

The most common condition leading to either outpatient or inpatient service use was hypertension 
Table 1 Demographic and socioeconomic characteristics in Mongolia, 2017-2018

\begin{tabular}{|c|c|c|c|c|}
\hline \multirow[t]{3}{*}{ Attributes } & & \multicolumn{3}{|c|}{ Percent $(n=975)$} \\
\hline & & \multirow{2}{*}{$\begin{array}{l}\text { Rural areas } \\
(n=478)\end{array}$} & \multicolumn{2}{|c|}{ Urban areas } \\
\hline & & & $\operatorname{ger}(n=255)$ & apartment $(n=242)$ \\
\hline \multirow[t]{2}{*}{ Sex } & Male & $43.9(210)$ & $34.9(89)$ & $33.5(81)$ \\
\hline & Female & $56.1(268)$ & $65.1(166)$ & $66.5(161)$ \\
\hline \multirow[t]{3}{*}{ Age Group } & $60-69$ & $62.6(299)$ & $69.4(177)$ & $47.1(114)$ \\
\hline & $70-79$ & $28.7(137)$ & $27.8(71)$ & $35.1(85)$ \\
\hline & $80+$ & $8.8(42)$ & $2.8(7)$ & $17.8(43)$ \\
\hline \multirow[t]{3}{*}{ Marital Status } & Married/Cohabiting & $63.8(305)$ & $51.8(132)$ & $53.7(130)$ \\
\hline & Not married* & $5.4(26)$ & $3.1(8)$ & $2.9(7)$ \\
\hline & Widowed & $30.8(147)$ & $45.1(115)$ & $43.4(105)$ \\
\hline \multirow[t]{3}{*}{ Ethnicity } & Mongol $^{\dagger}$ & $99.4(475)$ & $86.7(221)$ & $94.2(228)$ \\
\hline & Kazakł & $0.2(1)$ & $11.8(30)$ & $3.7(9)$ \\
\hline & Other & $0.4(2)$ & $1.6(4)$ & $2.1(5)$ \\
\hline \multirow[t]{4}{*}{ Religion } & None & $17.2(82)$ & $35.7(91)$ & $35.5(86)$ \\
\hline & Buddhist & $81.2(388)$ & $57.7(147)$ & $60.7(147)$ \\
\hline & Other & $1.0(5)$ & $6.7(17)$ & $3.3(8)$ \\
\hline & Missing & (3) & (0) & (1) \\
\hline \multirow[t]{6}{*}{ Educational Attainment } & No formal education & $5.1(24)$ & $1.6(4)$ & $1.6(4)$ \\
\hline & Primary school & $33.8(159)$ & $7.2(18)$ & $5.0(12)$ \\
\hline & Secondary school & $22.8(107)$ & $29.5(74)$ & $19.0(46)$ \\
\hline & High school & $12.6(59)$ & $15.5(39)$ & $19.4(47)$ \\
\hline & Tertiary or higher & $25.7(121)$ & $46.2(116)$ & $55.0(133)$ \\
\hline & Missing & (8) & (4) & (0) \\
\hline \multirow[t]{4}{*}{ Economic Tertiles } & Tertile 1 (lowest) & $41.6(162)$ & $29.4(68)$ & $24.9(48)$ \\
\hline & Tertile 2 & $39.6(154)$ & $29.0(67)$ & $22.3(43)$ \\
\hline & Tertile 3 (highest) & $18.8(73)$ & $41.6(96)$ & $52.9(102)$ \\
\hline & Missing & (89) & (24) & (49) \\
\hline
\end{tabular}

*includes never married $(n=12)$ and separated/divorced $(n=14)$

${ }^{\dagger}$ includes Khalkh, Dorwod, Bayad, Buriad, Zachin, Dariganga

₹ includes Kazak and the minority Turkic ethnicity Urianhai

[Table 2]. Notably, crude proportions of chronic joint and muscular pain were more common among females and hypertension among males. Reasons for health service use differed by sex $\left(\chi^{2} p=0.016\right)$ as well as between rural and the two urban areas $\left(\chi^{2}<0.001\right)$. Approximately $30 \%$ of correspondents reported one chronic condition, $30 \%$ reported at least two chronic conditions, $15 \%$ with three conditions, and $4 \%$ with four conditions and over.

Regarding health service accessibility, the most common mode of travel to outpatient services was public transport, particularly among urban (69.5\%) compared to rural residents $(42.1 \%)$, while using private vehicles was the most common mode of travel to in-patient services in both rural and urban areas [Table 3]. Travel times over an hour for outpatient and inpatient health service use was significantly higher in rural areas. Urban residents accessed a statistically significant higher proportion of free outpatient and inpatient services than rural residents (both $\chi^{2} p<0.001$ ) [Table 3].

When asked about satisfaction with the systems of health service delivery in Mongolia and how well services involve patients in decision-making, males and females reported similar responses [Table 3]. However, statistically significantly higher proportions of urban compared with rural residents were dissatisfied/very dissatisfied. There was no difference in reported satisfaction between urban ger and apartment areas.

In the adjusted multivariable logistic regression analyses [Table 4], females were almost double more likely than males to use outpatient health services. Older adults in the lowest economic tertile were statistically less likely to use outpatient services (AORs 0.63). Increasing numbers of chronic conditions (1 and $2+$ 
Table 2 Health service utilization by sex and urban-rural areas in Mongolia, 2017-2018

\begin{tabular}{|c|c|c|c|c|c|c|}
\hline \multirow[b]{2}{*}{$\%(n)$} & \multirow[t]{2}{*}{ Overall } & \multicolumn{2}{|c|}{ Sex } & \multicolumn{3}{|c|}{ Residence } \\
\hline & & Male & Female & Rural & Urban - ger & Urban - apartment \\
\hline \multicolumn{7}{|l|}{ Outpatient visits in the past year } \\
\hline Yes & $55.2(538)$ & $45.3(172)$ & $61.5(366)$ & $53.4(255)$ & $47.8(122)$ & $66.5(161)$ \\
\hline No & $44.8(437)$ & $54.7(208)$ & $38.5(229)$ & $46.7(223)$ & $52.2(133)$ & $33.5(81)$ \\
\hline \multicolumn{7}{|l|}{ Type of outpatient facility } \\
\hline Public clinic, including health centers & $62.8(337)$ & $59.9(103)$ & $64.1(234)$ & $55.5(141)$ & $68.8(84)$ & $69.6(112)$ \\
\hline Public hospital & $23.8(128)$ & $27.3(47)$ & $22.2(81)$ & $28.7(73)$ & $19.7(24)$ & $19.3(31)$ \\
\hline Private facilities & $11.2(60)$ & $10.5(18)$ & $11.5(42)$ & $11.0(28)$ & $11.5(14)$ & $11.3(18)$ \\
\hline Other & $2.3(12)$ & $2.3(4)$ & $2.2(8)$ & $4.7(12)$ & $\mathrm{n} / \mathrm{a}$ & $\mathrm{n} / \mathrm{a}$ \\
\hline \multicolumn{7}{|l|}{ Inpatient stays in the past 3 years* } \\
\hline Yes & $51.1(498)$ & $46.0(175)$ & $54.3(323)$ & $49.2(235)$ & $52.2(132)$ & $53.7(130)$ \\
\hline No & $48.9(477)$ & $53.9(205)$ & $45.7(272)$ & $50.8(243)$ & $47.8(122)$ & $46.3(112)$ \\
\hline \multicolumn{7}{|l|}{ Type of inpatient facility } \\
\hline Public hospital & $83.3(330)$ & $90.3(121)$ & $80.1(193)$ & $84.2(171)$ & $83.0(83)$ & $81.7(76)$ \\
\hline Private hospital & $13.6(54)$ & $6.7(9)$ & $17.8(43)$ & $11.3(23)$ & $15.0(15)$ & $17.2(16)$ \\
\hline Other & $3.0(12)$ & $3.0(4)$ & $2.1(5)$ & $4.4(9)$ & $2.0(2)$ & $1.1(1)$ \\
\hline \multicolumn{7}{|l|}{ Reasons for health service use ${ }^{* *}$} \\
\hline Acute or communicable conditions & 4.8 & 4.0 & 5.2 & 4.6 & 4.5 & 5.3 \\
\hline Chronic joint pain / arthritis & 14.9 & 10.9 & 16.9 & 16.2 & 11.1 & 15.9 \\
\hline Heart problems & 12.8 & 15.2 & 11.5 & 11.8 & 15.2 & 12.4 \\
\hline Hypertension & 31.6 & 32.6 & 31.1 & 32.1 & 30.3 & 31.9 \\
\hline Liver cirrhosis, liver cancer, other cancers & 3.2 & 4.3 & 2.6 & 2.6 & 4.0 & 3.5 \\
\hline Diabetes & 2.0 & 2.2 & 1.9 & 0.8 & 1.5 & 4.4 \\
\hline Other internal medicinet & 5.8 & 3.6 & 6.5 & 5.4 & 6.1 & 6.2 \\
\hline Otherł & 25.0 & 27.2 & 24.2 & 26.5 & 27.3 & 20.4 \\
\hline \multicolumn{7}{|l|}{ Chronic conditions } \\
\hline 0 & $18.7(184)$ & $27.1(103)$ & $12.3(73)$ & $24.9(119)$ & $13.3(34)$ & $9.5(23)$ \\
\hline 1 & $31.0(305)$ & $32.1(122)$ & $30.8(183)$ & $32.9(157)$ & $31.8(81)$ & $27.7(67)$ \\
\hline $2+$ & $50.2(494)$ & $40.8(155)$ & $56.9(339)$ & $42.3(202)$ & $54.9(140)$ & $62.8(152)$ \\
\hline
\end{tabular}

* Out of 498 respondents who had inpatient stays, 8 were reported in long-term care facility. ** either inpatient or outpatient; tincludes stomach, pancreas, kidney, gynaecological, prostate, bladder, haematological and nutritional disorders; generalised visceral or muscular pain; $\ddagger$ includes surgery, injuries, regular check-ups, breathing problems, sleep disorders, fatigue, allergies, hearing, vision, dental, neuropathy

compared to none) were associated with both outpatient (AORs 2.59 and 2.78) and inpatient (AORs 1.97 and 3.01) service use. There was no difference in use of outpatient and inpatient health services between rural residents and the combined urban population of ger and apartment areas. However, when further compared to apartment residents in urban areas, ger residents in urban areas were much less likely to use outpatient services (AORs 0.54).

Further stratified analyses by urban and rural areas reveal that females in rural areas were twice more likely than males to use outpatient services (Supplement Table 1). Chronic conditions were strong factors associated with both outpatient and inpatient service use in urban as well as rural areas. Notably, additional multivariable logistic regression analyses amongst outpatient and inpatient service users confirm that rural residents were over three times more likely to pay for outpatient services compared to urban-apartment residents (Supplement Table 2).

\section{Discussion}

This study investigates patterns and determinants of outpatient and inpatient health service use among older people in Mongolia. Slightly more than half of respondents reported outpatient health service use in the past 
Table 3 Accessibility and payment for health services and general satisfaction with health system services [percent, (n)] by sex and urban-rural areas in Mongolia, 2017-2018

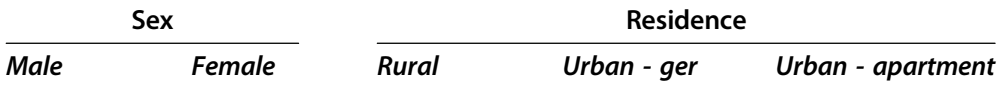

\begin{tabular}{|c|c|c|c|c|c|}
\hline \multicolumn{6}{|l|}{ Outpatient service use } \\
\hline \multicolumn{6}{|l|}{ Travel mode } \\
\hline Private vehicle & $34.2(53)$ & $22.6(75)$ & $37.7(86)$ & $15.3(17)$ & $16.9(25)$ \\
\hline Public Transport & $48.4(75)$ & $60.5(201)$ & $42.1(96)$ & $63.9(71)$ & $73.7(109)$ \\
\hline Taxi & $7.7(12)$ & $4.5(15)$ & $5.3(12)$ & $11.7(13)$ & $6.1(9)$ \\
\hline Walk & $9.7(15)$ & $12.4(41)$ & $14.9(34)$ & $9.0(10)$ & $3.4(5)$ \\
\hline \multicolumn{6}{|l|}{ Travel time } \\
\hline$<1$ hour & $86.9(140)$ & $87.9(312)$ & $82.1(197)$ & $94.2(113)$ & $91.0(142)$ \\
\hline$\geq 1$ hour & $13.0(21)$ & $21.1(43)$ & $17.9(43)$ & $5.8(7)$ & $9.0(14)$ \\
\hline \multicolumn{6}{|l|}{ Payment } \\
\hline Self or spouse & $11.4(18)$ & $7.4(26)$ & $11.9(27)$ & $6.6(8)$ & $5.6(9)$ \\
\hline Son/daughter or other family & $4.4(7)$ & $2.9(10)$ & $3.1(7)$ & $3.3(4)$ & $3.7(6)$ \\
\hline Insurance & $6.3(10)$ & $4.3(15)$ & $10.2(23)$ & $0.8(1)$ & $0.6(1)$ \\
\hline Free & $77.9(123)$ & $85.4(299)$ & $74.8(169)$ & $89.3(108)$ & $90.1(145)$ \\
\hline \multicolumn{6}{|l|}{ Inpatient service use } \\
\hline \multicolumn{6}{|l|}{ Travel mode } \\
\hline Private vehicle & $51.8(72)$ & $45.9(117)$ & $54.2(109)$ & $40.0(40)$ & $43.0(40)$ \\
\hline Public Transport & $9.4(13)$ & $14.1(36)$ & $6.5(13)$ & $22.0(22)$ & $15.1(14)$ \\
\hline Taxi & $14.4(20)$ & $20.8(53)$ & $13.4(27)$ & $25.0(25)$ & $22.6(21)$ \\
\hline Walk & $21.6(30)$ & $15.3(39)$ & $22.9(46)$ & $2.0(2)$ & $6.5(6)$ \\
\hline Ambulance & $2.9(2)$ & $3.9(10)$ & $3.0(6)$ & $11.0(11)$ & $12.9(12)$ \\
\hline \multicolumn{6}{|l|}{ Travel time } \\
\hline$<1$ hour & $79.4(108)$ & $73.5(186)$ & $71.5(143)$ & $78.4(76)$ & $81.5(75)$ \\
\hline$\geq 1$ hour & $20.6(28)$ & $26.5(67)$ & $28.5(57)$ & $21.7(21)$ & $18.5(17)$ \\
\hline \multicolumn{6}{|l|}{ Payment } \\
\hline Self or spouse & $20.0(28)$ & $17.5(45)$ & $23.0(47)$ & $12.0(12)$ & $15.0(14)$ \\
\hline Son/daughter or other family & $2.9(4)$ & $8.2(21)$ & $4.9(10)$ & $7.0(7)$ & $8.6(8)$ \\
\hline Insurance & $7.1(10)$ & $6.6(17)$ & $9.3(19)$ & $6.0(6)$ & $2.2(2)$ \\
\hline Free & $70.0(98)$ & $67.7(174)$ & $62.7(128)$ & $75.0(75)$ & $74.2(69)$ \\
\hline \multicolumn{6}{|c|}{ General satisfaction with health system services } \\
\hline Satisfied/very satisfied & $71.3(271)$ & $67.4(401)$ & $75.9(363)$ & $61.2(156)$ & $63.2(153)$ \\
\hline Neither & $21.3(81)$ & $24.0(143)$ & $21.1(101)$ & $25.9(66)$ & $23.6(57)$ \\
\hline Dissatisfied/very dissatisfied & $7.4(28)$ & $8.6(51)$ & $2.9(14)$ & $12.9(9)$ & $13.2(32)$ \\
\hline \multicolumn{6}{|c|}{ Service involvement of patient in decision-making } \\
\hline Satisfied/very satisfied & $46.8(178)$ & $46.1(274)$ & $50.2(240)$ & $43.5(111)$ & $41.7(101)$ \\
\hline Neither & $39.2(149)$ & $38.5(229)$ & $43.1(207)$ & $34.5(88)$ & $34.3(83)$ \\
\hline Dissatisfied/very dissatisfied & $13.9(53)$ & $15.5(92)$ & $6.5(31)$ & $21.9(56)$ & $23.9(58)$ \\
\hline
\end{tabular}

year. Urban ger area residents and rural residents were significantly less likely to have used outpatient services than urban apartment area residents.

The main disadvantages for rural residents were longer travel times than respondents living in urban areas for both outpatient and inpatient services and a higher proportion reporting out-of-pocket expenditure by self or spouse to pay for health services in rural areas. Notably, urban residents were three times more likely to express dissatisfaction with how health services are conducted 
Table 4 Fully adjusted multivariable logistic regression on determinants of outpatient and inpatient service use in Mongolia, 20172018

\begin{tabular}{|c|c|c|c|}
\hline \multirow[t]{2}{*}{ Attributes } & & \multicolumn{2}{|c|}{ Adjusted Odds Ratios [95\% Confidence Interval] } \\
\hline & & Outpatient use & Inpatient use \\
\hline \multicolumn{4}{|l|}{ Sex } \\
\hline & Male & Reference & Reference \\
\hline & Female & $\mathbf{1 . 8 8}[1.34 ; 2.63]$ & $1.27[0.91-1.77]$ \\
\hline \multicolumn{4}{|l|}{ Age group } \\
\hline & $60-69$ & Reference & Reference \\
\hline & $70-79$ & $1.00[0.56 ; 1.80]$ & $0.86[0.48 ; 1.52]$ \\
\hline & $80+$ & $1.65[0.55 ; 4.94]$ & $0.73[0.25 ; 2.15]$ \\
\hline \multicolumn{4}{|c|}{ Marital status } \\
\hline & Married/Cohabiting & Reference & Reference \\
\hline & Not married/Divorced & $1.44[0.68 ; 3.05]$ & $\mathbf{0 . 4 5}[0.21 ; 0.96]$ \\
\hline & Widowed & $0.92[0.64 ; 1.33]$ & $0.91[0.63 ; 1.30]$ \\
\hline \multicolumn{4}{|l|}{ Education } \\
\hline & Primary school or below & Reference & Reference \\
\hline & Secondary school & $1.02[0.66 ; 1.60]$ & $1.18[0.75 ; 1.82]$ \\
\hline & High school & $0.96[0.65 ; 1.41]$ & $1.32[0.99 ; 1.94]$ \\
\hline & Tertiary or higher & $0.85[0.54 ; 1.33]$ & $0.88[0.81 ; 1.69]$ \\
\hline \multicolumn{4}{|c|}{ Economic tertile } \\
\hline & Tertile 1 (lowest) & $0.63[0.41 ; 0.94]$ & $1.32[0.89 ; 1.98]$ \\
\hline & Tertile 2 & $0.73[0.50 ; 1.06]$ & $1.17[0.81 ; 1.70]$ \\
\hline & Tertile 3 (highest) & Reference & Reference \\
\hline \multicolumn{4}{|c|}{ Urban-rural areas } \\
\hline & Rural areas & $0.81[0.53 ; 1.23]$ & $1.12[0.74 ; 1.67]$ \\
\hline & Urban areas & & \\
\hline & ger & $0.54[0.36 ; 0.83]$ & $1.08[0.72 ; 1.63]$ \\
\hline & apartment & Reference & Reference \\
\hline \multicolumn{4}{|c|}{ Chronic conditions } \\
\hline & 0 & Reference & Reference \\
\hline & 1 & $2.59[1.66 ; 4.04]$ & $1.97[1.28 ; 3.07]$ \\
\hline & $2+$ & $2.78[1.82 ; 4.25]$ & $3.01[1.98 ; 4.57]$ \\
\hline
\end{tabular}

and their involvement in their health care decisionmaking.

Amongst older persons in low and middle-income countries in WHO SAGE, Mongolia had lower use of outpatient service (55\%) compared to $60-70 \%$ in China, Ghana, Russia, South Africa and $80 \%$ in India [17]. However, Mongolia had a much higher proportion of older people using inpatient services in the past three years (over $50 \%$ ) among respondents aged 60 years and over. The corresponding proportions in the immediate neighbouring countries for respondents aged 50 years and over were $22 \%$ in China and $30 \%$ in the Russian Federation $[19,24]$. Other countries in WHO SAGE including Ghana, India, Mexico, South Africa all reported less than $20 \%$ using inpatient services in the past three years. Notably, both Mongolia and Russia have continued high hospital use as part of the legacy of the Union of Soviet Socialist Republics health system between 1922 and 1991 [25]. These high health service utilization rates and a high number of hospital beds have been reported in former Soviet Union countries [26].

These results are similar to other countries where WHO SAGE surveys have been conducted, notably, respondents with two or more chronic conditions were twice or three times more likely to use health care services [20]. As well, aligned with other studies, older women were more likely than men to use outpatient services [19]. A plausible explanation is that men are more likely to delay accessing care, especially for less urgent chronic health conditions. Another explanation for 
higher use of outpatient use by women could be that older women have a higher prevalence of chronic disease. In the case of Mongolia, a chronic disease risk factor surveillance study found that females aged 55-64 years had a higher prevalence of NCDs than men ( $42.6 \%$ vs. $36.1 \%$ ) [23].

Within Mongolia, there are significant disparities between urban and rural areas in terms of distribution of health facilities and human resources, which are more concentrated in urban centres $[27,28]$. We found that older people living in urban ger areas had a much lower use of outpatient services than older people in apartment areas. Rural to urban migrants living in the outskirts of urban areas, in particular ger residents, face limited services in Family Health Centres (FHC) while the rural poor are strongly dependent on Soum Health Centres (SHC) with limited or no access to higher levels of health services [30]. Notably, this study reported significant differences in dissatisfaction with health services and involvement in health care decision making. Hence, policy design and service delivery would benefit from engaging older Mongolians to better understand their preferences and barriers to health service use. Future studies could also provide insights into motivations behind health care seeking behaviours among older Mongolians as the health system evolves.

Unofficial self-referrals to secondary and tertiary care have been well documented and are a fundamental challenge to the Mongolian health system [11-13]. Higher income individuals tend to bypass FHCs in urban areas and self-refer to higher level tertiary and specialised hospitals as they can afford the penalty fee leaving lower income urban-ger residence, especially rural to urban migrants with limited options [11-13]. Several factors relating to bypassing local primary health care have been attributed to unavailability of diagnostic capacities, treatment options and essential medicines [11, 13]. In order to strengthen and reorient services towards primary health, greater funding would enhance the range of service facilities and attract skilled health professionals in remote areas [12, 13].

Our data support previous findings from the Mongolian Household Socio-Economic Survey data 2007/2008, 2012, and 2018 that free access to health services does not guarantee equitable access $[11,13,30]$. Reasons given for not seeking treatment in the 2018 survey include the facility was too far or could not afford travel highlighting the influential role of geographic challenges compounded by a weak transport infrastructure [30]. Limited and scattered infrastructure in rural areas further contribute to widening geographical health service inequalities [11, 13, 29, 30].
Additionally, the Mongolian State Policy on Health (2017-2026) has promoted the use of mobile health screening or M-Health in combination with home visits and primary health care services in 21 provinces across Mongolia, including in Ulaanbaatar [27, 31]. These MHealth services help to not only reach out to disadvantaged communities, including migrants in urban-ger areas but also address geographical barriers for lowincome rural residents and nomadic populations in remote areas. Examples of $\mathrm{M}$-health screening services include health promotion for NCDs (e.g. monitoring cholesterol and blood sugar), preventative ultrasound and electrocardiogram examinations, and outreach services during COVID-19 [27, 31].

The main strength of the study lies in its international design using the WHO SAGE study materials and methods for research on the health of older people in low and middle-income countries [17, 18]. Our study also had a very high participation rate similar to other SAGE countries in Asia $85 \%$ in India and $93 \%$ in China) [18]. This study is the most comprehensive population-based study of the health of older people in Mongolia and complements previous NCD risk factor studies that used an upper age cut-off at 65 years [23]. There are study limitations that should be considered in interpreting results. The two rural aimag were purposively selected for logistic reasons and are relatively close to Ulaanbaatar. Greater rural-urban disparities may have been identified if more remote aimag had been studied. The study analysis has taken into account some individual-level determinants of health but not arealevel determinants, including the influence of lifestyle and living environment, and cultural resources such as social and familial support on health and health service use [10].

Primary health care is a cornerstone of UHC and sustainable development in many countries [32]. Evidence from Thailand, Sri Lanka and Malaysia has shown that availability and proximity of access to primary health care could favour older persons [33]. Recent evidence in Mongolia has reported the transformation of FHC and SHC under way towards health promotion (219 FHC and 273 SHC, $41.8 \%$ and $38.6 \%$ for outpatient visits for preventive purposes). According to the Asian Development Bank's three decades of partnership in Mongolia, primary health services might not yet meet expectations on the range and quality of services and will continue to require both financial and human resources as well as effective referral mechanisms across health services [34, 35].

\section{Conclusions}

With Mongolia's population ageing, the demand for health services will increase and may put further 
pressures on health equity for older people living in rural and urban ger areas. Findings also reveal that older Mongolians have relatively higher use of inpatient health care services and hence efforts to achieve UHC would benefit from reorienting care services towards prevention and primary care management of NCDs to facilitate accessibility and reduce the costs incurred from using hospital-based care.

\section{Abbreviations \\ AORs: Adjusted Odds Ratios; Cls: Confidence Intervals; FHC: Family Health Centres; NCDs: non-communicable diseases; OOP: Out-of-pocket expenditure; SHC: Soum Health Centres; UHC: Universal Health Coverage; WHO SAGE: World Health Organization Study on global AGEing and adult health}

\section{Supplementary information}

The online version contains supplementary material available at https://doi. org/10.1186/s12913-021-07156-y.

\section{Additional file 1.}

Additional file 2

\section{Acknowledgements}

The questionnaire and survey methods are based on WHO-SAGE instrument. Peter Sbirakos has provided editorial guidance on the latest version of the manuscript.

\section{Authors' contributions}

VSY, JGD, RGC drafted the manuscript. VSY and JGD carried out the statistical analyses. VSY, GD, JGD, PK, RGC participated in interpretation of the results. GD, UL, NN, PK, RGC conceived and designed the study. NN provided training on study materials and methods. $G D, B B, U L, D B, C O$ involved in the study implementation in Mongolia. VY, GD, JGD, PK, RGC reviewed and edited the manuscript. All authors approved the final manuscript.

\section{Funding}

This research was funded by University of Sydney Node of the Australian Research Council Centre of Excellence in Population Ageing Research (ARC CEPAR), grant number CE1701005.

\section{Availability of data and materials}

The datasets in the current study are not publicly available. Data, however, are available from the authors upon reasonable request.

\section{Declarations}

Ethics approval and consent to participate

The research was approved by the Research Ethics Committee of the Mongolian National University of Medical Sciences (2017/3-08). Written consent was obtained from study participants.

\section{Consent for publication}

Not applicable.

\section{Competing interests}

The authors declare that they have no competing interest.

\section{Author details}

${ }^{1}$ Australian Research Council Centre of Excellence in Population Ageing Research (CEPAR), University of New South Wales, Sydney, Australia. ${ }^{2}$ School of Public Health, Mongolian National University of Medical Sciences, Ulaanbaatar, Mongolia. ${ }^{3}$ Faculty of Medicine and Health, The University of Sydney, Camperdown, Australia. "World Health Organization, Geneva, Switzerland. ${ }^{5}$ International Health Transitions, Canberra, Australia.
Received: 30 October 2020 Accepted: 11 October 2021

Published online: 30 October 2021

\section{References}

1. WHO: World Report on Ageing and Health 2015. Geneva: World Health Organization.

2. World Bank:: Live Long and Prosper: Aging in East Asia and Pacific. Washington DC: Internatonal Bank for Reconstruction and Development/ The World Bank.

3. Barber SL, Rosenberg M. Aging and universal health coverage: Implications for the Asia Pacific region. Health Syst Reform. 2017:3(3):154-8.

4. United Nations. World Population Prospects 2019, custom data acquired via website. Department of Economic and Social Affairs, Population Division;" 2019.

5. World Bank.: World Development Indicators. Washington DC. data. worldbank.org/indicator; 2020.

6. GBD.: Global Burden of Diseases (GBD) Compare. Seattle, Washington: Institute for Health Metrics and Evaluation; 2017.

7. Dugee O, Sugar B, Dorjsuren B, Mahal A. Economic impacts of chronic conditions in a country with high levels of population health coverage: lessons from Mongolia. Trop Med Int Health. 2019;24(6):715-26.

8. Znaor A, Chimed T, Laversanne M, Tudev U, Sanjaajamts E, Sandagdorj T, Bray F. The public health challenge of liver cancer in Mongolia. Lancet Gastroenterol Hepatol. 2018:3(10):660-2.

9. Mongolian National Statistics Office. Population. Ulaanbaatar: National Statistics Office; 2018.

10. So YLN, Kim S, Lee Y, Ochir C, Lee K. Characteristics of lifestyle and living environment of Ger district residents in Ulaanbaatar, Mongolia. Korean Journal of Public Health. 2018;55(2):12-21.

11. Dorjdagva J, Batbaatar E, Svensson M, Dorjsuren B, Batmunkh B, Kauhanen J. Free and universal, but unequal utilization of primary health care in the rural and urban areas of Mongolia. Int J Equity Health. 2017;16(1):73.

12. Tsilaajav T, Ser-Od E, Baasai B, Byambaa G, Shagdarsuren O. Mongolia Health System Review. Vol. 3. Manila: World Health Organization, Regional Office for the Western Pacific: 2013

13. Jigjidsuren A, Byambaa T, Altangerel E, Batbaatar S, Saw YM, Kariya T, Yamamoto E, Hamajima N. Free and universal access to primary healthcare in Mongolia: the service availability and readiness assessment. BMC Health Serv Res. 2019;19(1):129.

14. Dorjdagva J, Batbaatar E, Dorjsuren B, Kauhanen J. Explaining differences in education-related inequalities in health between urban and rural areas in Mongolia. Int J Equity Health. 2015;14:154

15. Hogan DR, Stevens GA, Hosseinpoor AR, Boerma T. Monitoring universal health coverage within the Sustainable Development Goals: development and baseline data for an index of essential health services. Lancet Glob Health. 2018:6(2):e152-68.

16. Lhamsuren K, Choijiljav T, Budbazar E, Vanchinkhuu S, Blanc DC, Grundy J. Taking action on the social determinants of health: improving health access for the urban poor in Mongolia. Int J Equity Health. 2012;11:15.

17. He W, Muenchrath MN, Kowal P. Shades of Gray: A Cross-Country Study of Health and Well-Being of the Older Populations in SAGE Countries, 2007-2010. In: International Population Reports. Washington, DC: US Census Bureau; 2012.

18. Kowal P, Chatterii S, Naidoo N, Biritwum R, Fan W, Lopez Ridaura R, Maximova T, Arokiasamy P, Phaswana-Mafuya N, Williams S, et al. Data Resource Profile: The World Health Organization Study on global AGEing and adult health (SAGE). Int J Epidemiol. 2012;41(6):1639-49.

19. Peltzer K, Williams IS, Kowal P, Negin J, Snodgrass JJ, Yawson A, Minicuci N, Thiele L, Phaswana-Mafuya N, Biritwum RB, et al. Universal health coverage in emerging economies: findings on health care utilization by older adults in China, Ghana, India, Mexico, the Russian Federation, and South Africa. Glob Health Action. 2014;7:25314.

20. Awoke MA, Negin J, Moller J, Farell P, Yawson AE, Birtitwum RB, Kowal P. Predictors of public and private healthcare utilization and associated helath system responsiveness among older adults in Ghana. Glob Health Action. 2017;10:1301723.

21. IBM Corp. Released 2017. IBM SPSS Statistics for Windows. Armonk, NY: IBM Corp.

22. StataCorp. Stata Statistical Software: Release 16. College Station. TX: StataCorp LLC; 2019

23. Public Health Institute Mongolia:: Third national STEPS Survey on the Prevalence of Noncommunicable Disease and Injury Risk Factors-2013. Ulaanbaatar Ministry of Health and Sports; 2013. 
24. WHO. Study on global AGEing and adult health (SAGE). In: Wave 1 Russian Federation National Report. National Research Institute of Public Health, Russian Academy of Medical Sciences. Geneva: World Health Organization; 2014.

25. World Bank: The Mongolian Health System at a Crossroads: An Incomplete Transition to a Post-Semashko Model. Working Paper Series No. 2007-1. Washington DC: Human Development Sector Unit East Asia and the Pacific Region; 2007.

26. Glonti K: Specialised and inpatient services. In: Trends in health systems in the former Soviet services. edn. Edited by Rechel B, Richardson E, McKee M. World Health Organization: European Observatory on Health Systems and Policies; 2014.

27. Erdenee O, Paramita SA, Yamazaki C, Koyama H. Distribution of health care resources in Mongolia using the Gini coefficient. Hum Resour Health. 2017; 15(1):56.

28. Gan-Yadam A, Shinohara R, Sugisawa Y, Tanaka E, Watanabe T, Hirano M, Tomisaki E, Morita K, Onda Y, Tokutake K, et al. Factors associated with health service utilization in Ulaanbaatar, Mongolia: a population-based survey. J Epidemiol. 2013;23(5):320-8.

29. National Statistics Office. Health. General Statistical Database: National Statistics Office 2020

30. Uochi I. Mongolia poverty update 2018: Main report of household socio-economic survey. Ulaanbaatar: National Statistics Office of Mongolia; 2020

31. World Health Organization. Mongolia's mobile health clinics bring primary health care to vulnerable communities. https://www.who.int/news-room/fea ture-stories/detail/mongolia-s-mobile-health-clinics-bring-primary-health-ca re-to-vulnerable-communities. March 2021.

32. Chotchoungchatchai S, Marshall Al, Witthayapipopsakul W, Panichkriangkrai W, Patcharanarumol W, Tangcharoensathien V. Primary health care and sustainable development goals. Bull World Health Organ. 2020;98(11):792-800.

33. Yiengprugsawan V, Healy J, Kendig H, Neelamegam M, Karunapema P, Kasemsup V. Reorienting health services to people with chronic health conditions: diabetes and stroke services in Malaysia, Sri Lanka and Thailand. Health Systems Reform. 2017;3(3):171-81.

34. Jigijidsuren A, Oyun B, Habib N. Supporting primary health care in Mongolia. Experiences, lessons learned, and future directions. ADB East Asia Working Paper Series. No. 35. Manila: Asian Development Bank, 2021.

35. ADB. Country diagonostic study on long-term care in Mongolia. Manila: Asian Development Bank; 2020

\section{Publisher's Note}

Springer Nature remains neutral with regard to jurisdictional claims in published maps and institutional affiliations.

Ready to submit your research? Choose BMC and benefit from:

- fast, convenient online submission

- thorough peer review by experienced researchers in your field

- rapid publication on acceptance

- support for research data, including large and complex data types

- gold Open Access which fosters wider collaboration and increased citations

- maximum visibility for your research: over $100 \mathrm{M}$ website views per year

At BMC, research is always in progress.

Learn more biomedcentral.com/submissions 